\title{
Shaping of Peripheral T Cell Responses by Lymphatic Endothelial Cells
}

\author{
Marion Humbert, Stéphanie Hugues* and Juan Dubrot* \\ Department of Pathology and Immunology, University of Geneva Medical School, Geneva, Switzerland
}

Lymph node stromal cells (LNSCs) have newly been promoted to the rank of new modulators of $\mathrm{T}$ cell responses. The different non-hematopoietic cell subsets in lymph node $(L N)$ were considered for years as a simple scaffold, forming routes and proper environment for antigen (Ag)-lymphocyte encountering. Deeper characterization of those cells has recently clearly shown their impact on both dendritic cell and $T$ cell functions. In particular, lymphatic endothelial cells (LECS) control lymphocyte trafficking and homeostasis in LNs and limit adaptive immune responses. Therefore, the new role of

Edited by: Sonia Elhadad, Weill Cornell Medical College, USA

Reviewed by:

Hideki Nakano,

National Institute of Environmental Health Sciences, USA

Ingrid E. Dumitriu,

St. George's University

of London, UK

Beth Ann Tamburini,

University of Colorado Denver, USA

*Correspondence:

Stéphanie Hugues stephanie.hugues@unige.ch; Juan Dubrot

juan.dubrotarmendariz@unige.ch

Specialty section:

This article was submitted to Inflammation,

a section of the journal

Frontiers in Immunology

Received: 21 October 2016 Accepted: 22 December 2016 Published: 12 January 2017

Citation:

Humbert M, Hugues S and Dubrot J (2017) Shaping of Peripheral T Cell Responses by Lymphatic Endothelial

Cells.

Front. Immunol. 7:684. doi: 10.3389/fimmu.2016.00684
LECs in shaping immune responses has drawn the attention of immunologists. Striking is the discovery that LECs, among other LNSCs, ectopically express a large range of peripheral tissue-restricted Ags (PTAs), and further present PTA-derived peptides through major histocompatibility class I molecules to induce self-reactive $\mathrm{CD}^{+} \mathrm{T}$ cell deletional tolerance. In addition, both steady-state and tumor-associated LECs were described to be capable of exogenous Ag cross-presentation. Whether LECs can similarly impact $\mathrm{CD}^{+} \mathrm{T}$ cell responses through major histocompatibility class II restricted Ag presentation is still a matter of debate. Here, we review and discuss our current knowledge on the contribution of Ag-presenting LECs as regulators of peripheral $\mathrm{T}$ cell responses in different immunological contexts, including autoimmunity and cancer.

Keywords: lymphatic endothelial cells, peripheral tissue antigens, antigen presentation, immunomodulation, tolerance

\section{INTRODUCTION}

The lymphatic system comprises a network of vessels together with lymphoid tissues all over the body that drain the extracellular compartment from most of the tissues. It transports lymph fluid, which is composed of immune cells and proteins drained from interstitial tissues, and helps to dispose of toxins and other unwanted components from the body. Lymphocytes follow the lymphatic system to migrate to infection sites, which supports and facilitates immune responses against potential harms. Frequently underestimated by scientists, the importance of lymphatics in controlling the immune system beyond the regulation of leukocyte trafficking has reached a new level with recent discoveries.

The initial observations of the lymphatic system date back to the Ancient Greece, referred to as "white blood." However, it was in the seventeenth century that Asellius formally discovered the lymphatic vessels or, what he called, the "milky veins" from mesenteries in dogs (1). Several diseases have been described to result from failures in the lymphatic system, some of them having lifethreatening consequences, such as lymphedema (2). Even more strikingly, the role of lymphatics in 
tumor spreading is known since the eighteenth century. Despite the ancient knowledge in the lymphatic system organization, our understanding in its multiple functions has rapidly evolved thanks to the unveiling of lymphatic endothelial cell (LEC) specific markers, such as the surface protein Lyve-1 or the transcription factor Prox-1, which are lacking in other endothelial cells. Several studies have subsequently demonstrated that LECs impact immune responses in many ways, including the modulation of immune cell migration and encounter, effector functions, and survival. In this review, we discuss our current understanding of the imunoregulatory properties of LECs. We specifically discuss the ability of LECs to directly impact $\mathrm{T}$ cell responses by presenting endogenous or exogenous antigens (Ags) to T cells in lymph nodes (LNs), and therefore to shape Ag-specific peripheral $\mathrm{T}$ cell responses in the context of autoimmunity and cancers.

\section{ORIGIN AND TYPES OF LYMPHATICS}

\section{LEC Development}

Nowadays, it is well accepted and documented that, during embryogenesis, LECs differentiate from specialized angioblasts in the developing veins $(3,4)$. Nevertheless, this has been controversial for long until just few decades ago due to, in particular, the lack of knowledge on lymphatic-specific markers. Two different hypotheses raised in early twentieth century debated the possible origin of the lymphatic system. On one hand, studies on embryonic cats suggested that primary lymph sacs arised from mesenchymal progenitors (5). On the other hand, intravenous injection of ink in pig embryos revealed that lymph sacs developed from budding of embryonic veins $(6,7)$. The identification of the vascular endothelial growth factor receptor-3 (VEGFR-3) (8) reinforced the latter hypothesis of a common origin for both lymphatic and blood endothelial cells (BECs). In adulthood, VEGFR-3 expression is restricted to LECs $(8,9)$. However, it is also expressed by angioblasts and developing veins during embryonic development $(8,10,11)$. Impaired development of both lymphatic and blood endothelium in VEGFR-3-deficient mice suggested a common progenitor for LECs and BECs (11). Further ratification of VEGFR-3 requirement for lymphatic development was provided by studies modulating the expression of its main ligand, the vascular endothelial growth factor C (VEGF-C). Overexpression of VEGF-C induced lymphatic sprouting and lymphangiogenesis (12-14).

The identification of the homeobox gene Prox-1 in 1993 led few years later to the final confirmation of the theory proposing the venous origin of lymphatics. Deletion of Prox-1 in mice results in the absence of early lymphatic endothelial differentiation and, as a consequence, Prox-1 knockout mice totally lack the lymphatic system $(10,15)$. Prox-1 expression in particular cells of the embryonic veins at E9.5 starts the lymphatic polarization and imprints the LEC signature $(10,15,16)$. Transcriptome studies showed high proximity in LECs and BECs gene expression profiles. However, Prox-1 acts as the specific regulator of genes that are inversely regulated in a type-specific manner $(17,18)$. Indeed, potentially all venous endothelial cells may give rise to blood or lymphatic endothelium as demonstrated by Prox-1-induced reprograming when overexpressed in BECs (16). After development, functional Prox-1 is required to maintain the lymphatic phenotype (19). The molecular mechanisms of Prox-1-driven lymphatic differentiation have been reviewed recently (4). In addition, recent studies in zebrafish validated the molecular mechanisms governing lymphatic development, further demonstrating that the vast majority of cells contributing to LECs in thoracic ducts of zebrafish raised from primitive veins $(3,20)$. Later in development, however, the origin of organspecific lymphatic vasculature might be slightly different. Using cell-fate mapping technologies, a recent publication suggested a combination of venous- and non-venous-derived LECs in the developing cardiac lymphatics (21). This spatiotemporal discrepancy may explain the difficulties experienced in obtaining a fully convincing explanation in the origin of LECs.

The specification of LECs during development entails structural and functional differences between blood and lymphatic systems. In sharp contrast to the circular and closed blood vasculature, lymphatic circulation appears as a linear- and blind-ended circuit. Capillaries of the lymphatic system drain interstitial fluids from peripheral organs and tissues thanks to the particular organization of LECs in the terminal lymphatics. The uptake of interstitial fluid, macromolecules, and cells is possible due to the highly permeable thin-walled capillary vessels composed of a single layer of LECs, which are not covered by pericytes or smooth muscle cells and have little or no basement membrane (22). Lymphatic capillaries exhibit discontinuous or "button-like" junctions where the interjunctional gaps act as sites of leukocyte entry into the vessels $(23,24)$. Terminal lymphatic capillaries are linked to the surrounding extracellular matrix by anchoring filaments that sense changes in interstitial pressures during inflammation. This results in vessel lumen and junction aperture, therefore facilitating the uptake of tissue-derived fluids. Deeper, lymphatics change from a drainage-prone phenotype to a collector vessel morphology specialized in lymph transport. Collecting lymphatics are surrounded by pericytes and smooth muscle cells and possess a basement membrane, displaying continuous "zipper-like" junctions. The presence of valves $(22,23)$ ensures the lymph circulation while preventing retrograde flow.

\section{Main LEC Types}

Lymphatic vessels are present in almost all the vascularized organs, with the exception of the bone marrow. LEC immune modulatory properties represent a growing research area. LN LECs being the most characterized subset and representing the objective of this review is not discussed in this section.

However, lessons taken from studies performed during the last decade clearly establish different functions and possible roles for LECs from different anatomic locations. Deeper and careful future analyses will identify specific immunoregulatory features of distinct LEC populations.

For decades, lymphatic drainage was suggested to be involved in local immune responses (25). Dendritic cells (DCs) draw all the attention in initiating and eliciting tolerance or activation of the immune system. However, the role of lymph drainage in modulating adaptive immunity and tolerance remained largely unexplored. K14-VEGFR-3-Ig mice express soluble VEGFR-3-Ig 
via the keratin 14 promoter, resulting in a lack of lymphatic growth, which is restricted to the skin, and in a drop in fluid clearance (26). In these mice, local lymphatic drainage appeared to be critical for humoral immunity and acquired tolerance, while $\mathrm{T}$ cell responses remained delayed but mostly unaffected. There is no doubt that additional mechanisms and functions of dermal LECs will be discovered in the future.

LSECs could be seen as LEC counterparts in the liver. First described in 1970 (27), LSECs possess a high ability to filter fluids, solutes, and particles from hepatic circulation, occupy a large surface area exposed to blood that carries external food and commensal bacterial Ag, and are known to cross-present exogenous Ag to T cells (28).

A traditional dogma states the immune privilege and lack of lymphatic system in the central nervous system (CNS). This idea has persisted despite the notion of immune surveillance of $\mathrm{T}$ cells in the brain (29). A recent and elegant study identified for the first time the lymphatic vasculature in a specific area of the meninges lining the dural sinuses (30). The vessels express LEC-specific markers such as Lyve-1, Prox-1, or Podoplanin and drain the cerebrospinal fluid to deep cervical LNs. These findings provide new insights in the establishment and progression of some neurological diseases involving immune cell contribution, such as multiple sclerosis or Alzheimer's. Moreover, CNS-resident stromal fibroblastic and endothelial cells were shown to guide antiviral $\mathrm{CD}^{+} \mathrm{T}$ cell responses in a model of virus-induced neuroinflammation (31). The production of CCR7 ligands CCL19 and CCL2 1 by CNS stromal cells was found critical for the induction of viral-specific T cell recruitment and the support of local $\mathrm{T}$ cell reactivation. Whether newly discovered CNS lymphatics (30) similarly contribute to neuroinflammatory immunopathologies remains to be determined.

Lymphatic development in the tumor microenvironment, known as tumor lymphangiogenesis, has been extensively studied. The participation of tumor lymphatics in the spread of the disease, or metastasis, has been studied for many years. In fact, most human melanomas and carcinomas metastasize through the lymphatic system (32). The presence of tumor-associated LECs correlates with bad clinical outcome in several types of cancer (33) and therapies aiming the blockade of tumor lymphangiogenesis are being considered for treatment of such malignancies (34). Growing evidence highlight the impact of tumor-associated LECs in dampening antitumor immunity. How interactions between lymphatics and $\mathrm{T}$ cells in the context of tumor development will further alter $\mathrm{T}$ cell responses is discussed below.

\section{Ag PRESENTATION INDEPENDENT IMPACT OF LECS ON PERIPHERAL T CELL RESPONSES}

Hallmarks of T cell immunity include the generation of pathogenspecific effector responses to confer protection against a large range of invaders, without causing unwanted self-tissue damage. Naïve T cells constantly scan for their cognate Ag. However, given the extremely low frequency of T cells being specific for a particular peptide-major histocompatibility (MHC) complex $(35,36)$, this challenging task is strictly located into highly organized secondary lymphoid organs (SLOs), such as LNs, Peyer's patches (PPs), and the spleen. These SLOs contain both tissue-derived and blood-borne Ags, therefore facilitating naïve T cell-Ag encounter, and subsequent $\mathrm{T}$ cell activation and differentiation into $\mathrm{T}$ cell effectors. This part summarizes the different pathways by which LECs will impact $\mathrm{T}$ cell outcome inside and after exiting LNs.

\section{Ag Delivery to LNs}

As described before, LNs are connected to lymphatics, which drain peripheral tissue-derived fluids. By connecting tissues to draining LNs, LECs facilitate the passive entry of tissue-derived Ags that can thereby be captured, processed, and presented by resident DCs to T cells entering LNs through high endothelial venules $(37,38)$. Soluble Ags are immediately sampled by LN DCs, whereas particles carrying Ags, such as exosomes, apoptotic bodies or microvesicles, which have not been captured by subcapsular sinus macrophages, flow to LN medullary sinuses where they can be sampled by DCs (39). LECs also support the active migration of tissue-resident DCs into LNs. DC migration from tissues to draining LNs via lymphatic vessels is an important way to present Ags and activate naïve T cells. DCs enter afferent lymphatics through preformed portals (40), independent of integrin-mediated adhesion (41). However, LECs upregulate adhesion molecules upon inflammation, further favoring DC access to lymphatic vessels (42). In addition, expression of CLEC2 (a C-type lectin receptor) by DCs promotes their migration to LNs via lymphatics through interaction with its ligand gp38 (Podoplanin), which is expressed by both LECs and fibroblastic reticular cells (FRCs) (43).

\section{Modulation of DC Functions}

Tissue-resident DCs having acquired peripheral Ags subsequently migrate through afferent lymphatics into LNs in a CCR7-dependent manner. However, the lymphatic system does not only support DC migration from tissues to LNs. Indeed, close interactions between migrating DCs and LECs induce phenotypic and functional changes in DCs. First, contacts between TNF- $\alpha$-stimulated LECs and DCs lead to decreased expression of costimulatory molecules by DCs in vitro, thus impairing DC ability to induce T cell proliferation (44). LECmediated regulation of DC functions is dependent on interactions between CD11b (Mac-1) on DCs and ICAM-1 on LECs (44). Interestingly, LECs are able to inhibit the function of LPS-activated DCs, suggesting once again a regulatory role for LECs in the resolution phase of inflammation. A recent report demonstrated that LECs function as reservoirs of peripheral tissue-restricted Ags (PTAs), which are subsequently acquired and presented by DCs to induce T cell anergy, therefore contributing to peripheral $\mathrm{CD} 4^{+} \mathrm{T}$ cell tolerance $(45)$.

\section{T Cell Homeostasis}

While T cell migration inside LNs is mainly driven by CCL19 and CCL21 produced by FRCs (46), naive and memory T lymphocyte maintenance in SLOs is highly dependent on IL-7. Together with FRCs (47), LECs represent an important source of IL-7 in vivo, regulating lymphocyte homeostasis and access to SLOs. IL-7-GFP 
knock-in mice exhibit moderate GFP expression in LN-FRCs, whereas high levels were detected in both LN LECs and tissue LECs $(48,49)$. Similarly, LECs were shown to be the major source of IL-7 in both human and murine LNs (50). Furthermore, LECs not only produce IL-7 but also express the IL-7 receptor chains IL-7R $\alpha$ and CD132, suggesting a possible role for IL-7 as an autocrine mediator of lymphatic drainage. IL-7-stimulated LECs induced lymphangiogenesis in the cornea of mice in vitro, whereas in IL-7 $\mathrm{R}^{-/-}$mice, lymphatic drainage was compromised (51). In addition, IL-7 upregulation by both FRCs and LECs is essential for $\mathrm{LN}$ reconstruction and remodeling following viral infection or avascular transplantation (50). This suggests that IL-7 production in LN after resolution of an infection could be involved in memory $\mathrm{T}$ cell homeostasis. Accordingly, IL-7 promotes the development, the proliferation, and the survival of memory CD8 ${ }^{+} \mathrm{T}$ cells $(52,53)$.

\section{T Cell Egress from LNs}

$\mathrm{T}$ cell egress from LNs is dependent on their expression of the sphingosine-1-phosphate (S1P) receptor (S1PR1). Using mice lacking S1P selectively in LECs while maintaining normal blood S1P, Cyster and collaborators have shown that LECs are an in vivo source of $\mathrm{S} 1 \mathrm{P}$ in LNs, allowing $\mathrm{T}$ cell egress from LNs and PPs (54). S1PR1 expression is downregulated by blood circulating lymphocytes, and upregulated in LNs. Interactions between S1P-producing LECs and S1P1R-expressing $\mathrm{T}$ cells promote LN egress by overcoming retention signals mediated by CCR7 $(55,56)$. Although steady-state LECs express low levels of S1P, its production is upregulated in medullary sinus LECs upon PAMP/DAMP-mediated inflammation, suggesting that high S1P-expressing LECs can promote effector T cell egress from LNs in pathogenic situations. In contrast, in non-infectious sterile inflammatory contexts, low S1P-producing LECs would rather dampen $\mathrm{T}$ cell effector functions by favoring $\mathrm{T}$ cell retention in LNs.

\section{T Cell Migration in Tumor-Associated Lymphatics}

Increasing evidence suggest that tumor-associated lymphatics not only simply function as tumor cell transporters but also play additional important roles impacting tumor development. Accordingly, not only metastatic but also primary tumor progression can be affected by modulating tumor-associated lymphatic expansion. In the context of solid tumors, lymph flow from tumors is elevated, driving intense interstitial flow in the tumor stroma and increasing lymphatic drainage from the tumor to the draining LN (57). Combined with a suppressive cytokine environment, it is therefore possible that increased tumor Ags drainage could promote tumor-specific T cell dysfunction, including anergy and apoptosis. In addition, the lymph supports cells migrating from tissues, in particular CCR7 $7^{+} \mathrm{DCs}$, a phenomenon shown to be critical for initiating antitumor immune responses (58).

Tumor infiltration by $\mathrm{T}$ cells is one of the key steps in antitumor immunity. While cytotoxic T lymphocyte infiltration correlates with good prognosis, accumulation of $\mathrm{T}$ regulatory cells (Treg) or naïve $\mathrm{T}$ cells is detrimental for the clinical outcome $(59,60)$.
Likewise, expression of CCL21 in the tumor promotes immune escape and tumor progression (61), which may be explained, at least in part, by the enhancement of naïve $\mathrm{T}$ cell recruitment. Although $\mathrm{T}$ cell receptor (TCR)-transgenic tumor-infiltrating naïve $\mathrm{T}$ cells may be activated in situ (62), it is unlikely, given the immunosuppressive tumor-related environment, that this will lead to fully competent effector $\mathrm{T}$ cell differentiation. In this regard, it is still to be demonstrated whether CCL21-producing LECs contribute to this effect. How LECs contribute to the overall tolerogenic properties of the tumor microenvironment is still an open question.

We have demonstrated that the lymphangiogenic growth factor VEGF-C produced in the tumor promoted immunological tolerance in murine melanoma (63). VEGF-C protected tumors against preexisting antitumor immunity and promoted local deletion of tumor-specific $\mathrm{CD}^{+} \mathrm{T}$ cells $(63,64)$. Our findings introduce a new role for lymphatics in promoting tumor development and suggest that lymphatic endothelium in the local microenvironment may be a novel target for immunomodulation. Supporting those hypotheses there is a recent publication demonstrating that following exposure to tumor-derived factors, FRCs of the tumor-draining LNs adapt on multiple levels to exhibit features associated with immunosuppression, such as decreased production of IL-7 and CCL19/21 (65). Whether a similar profound reprograming occurs to LECs in tumor-draining LNs remains to be determined.

\section{Ag PRESENTATION-DEPENDENT IMPACT OF LECs ON PERIPHERAL T CELL RESPONSES}

In addition to their ability to modulate $\mathrm{T}$ cell responses by impacting immune cell migration, interactions, and homeostasis, LECs can also function as Ag-presenting cells through several mechanisms and directly influence peripheral T cell outcome.

\section{Presentation of Endogenously Expressed PTAs to T Cells by LECs}

In order to prevent autoimmunity, thymocytes go through a process of negative selection, part of the so-called central tolerance, allowing the deletion of autoreactive $\mathrm{T}$ cell clones before they exit from the thymus to enter into the periphery [reviewed in Ref. (66, 67)]. In the thymus, medullary thymic epithelial cells (mTECs) promiscuously express PTAs, Ag that are normally expressed in the periphery $(68,69)$. The expression of a vast majority of PTAs in mTECs is regulated by transcription factors (70), including the autoimmune regulator (Aire), mutations in Aire leading to severe autoimmune disorders $(71,72)$. PTAs can be either directly presented by mTECs to the thymocytes, acquired from mTECs by thymus-resident DCs or acquired in tissues by migrating DCs or plasmacytoid DCs (pDCs), and cross-presented to the thymocytes (73-76) (Figure 1A). Thymocytes expressing a TCR with a too high affinity for self- $\mathrm{Ag} / \mathrm{MHC}$ complexes undergo clonal deletion (73-75). A fraction of the $\mathrm{CD} 4^{+}$thymocytes having a TCR with a high affinity differentiates into thymus-derived Tregs (tTregs), previously called natural Tregs (nTregs), and expresses 


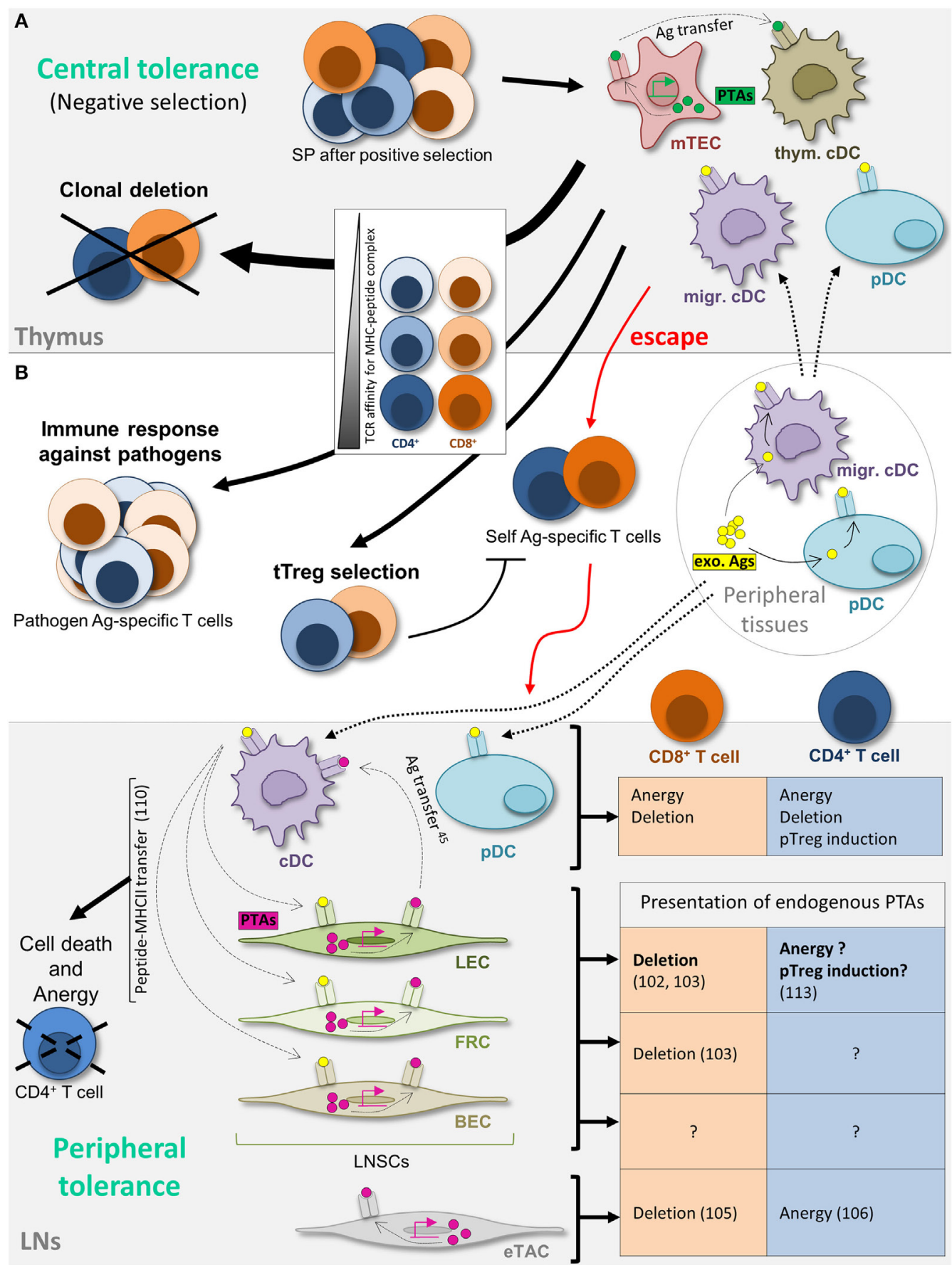

FIGURE 1 | Maintenance of T cell tolerance. (A) Schematic view of thymic central tolerance, reviewed in Ref. (67). After positive selection (not depicted), simple positive (SP) thymocytes undergo a process of negative selection. Thymus-resident conventional dendritic cells (cDCs) and peripheral tissue-restricted antigens (Ags) (PTA) (green)-expressing medullary thymic epithelial cells, as well as peripheral plasmacytoid DCs (pDCs) and cDCs, that have acquired Ag (yellow) in the periphery and migrate to the thymus, present self-peptide major histocompatibility complex (MHC) complexes to SP thymocytes. Thymocytes expressing a T cell receptor (TCR) with high affinity for self (dark colors) are clonally deleted. SP expressing a TCR with intermediate affinity differentiate into thymus-derived T regulatory cell (tTreg) (medium colors). Low-affinity TCR-expressing SP (light colors) exit from the thymus and enter the periphery, however comprising some self-reactive T cells (dark colors) that escaped central tolerance. (B) Peripheral T cell tolerance in the lymph nodes (LNs). References related to lymph node stromal cell contributions are indicated (numbers). Self-Ag-specific T cell tolerance is further maintained in the periphery in LNs. cDCs and pDCs acquire Ag from peripheral tissues (yellow) and migrate to LNs to present Ag to autoreactive T cells. cDCs also acquire Ag expressed by lymphatic endothelial cells (LECs). LECs, fibroblastic reticular cells, and blood endothelial cells present endogenously expressed PTAs (pink), as well as peptide-MHC-II complexes acquired from cDCs, therefore contributing to peripheral T cell tolerance via distinct mechanisms. Extrathymic autoimmune regulator (Aire)-expressing cells (eTACs) present endogenously expressed PTAs. The outcome of Ag presentation by each cell subtype is depicted in the figure. Cell migration and Ag transfer are represented by dotted and dashed arrows, respectively. exo Ags, exogenous antigens; migr. cDC, migratory cDC; pTreg, peripherally induced Treg; thym. cDC, thymus-resident cDC. 
the transcription factor Foxp3 (77). A population of CD8 ${ }^{+}$Foxp $^{+}$ tTregs has also been described (78-81). However, some autoreactive-non-Treg- $\mathrm{T}$ cells do escape thymic central tolerance mechanisms and reach the periphery $(82,83)$, as a result from either an absence of specific self-Ag presentation in the thymus, or a lack of deletion due to a TCR exhibiting an affinity for self$\mathrm{Ag} / \mathrm{MHC}$ complexes below the negative selection threshold (84) (Figure 1A).

Therefore, additional mechanisms, called peripheral tolerance mechanisms, have evolved to maintain $\mathrm{T}$ cell tolerance apart from the thymus [reviewed in Ref. $(66,85)]$. Cross-tolerance induction by peripheral DCs has been extensively studied and reviewed over the past two decades (86); immature DCs acquire Ag through the phagocytosis of apoptotic cells in peripheral tissues to present them to T cells in SLOs (87-89). In the absence of costimulatory signals, Ag presentation leads to $\mathrm{CD} 4^{+}$and $\mathrm{CD}^{+}$ $\mathrm{T}$ cell clonal deletion (physical elimination) or anergy (functional inactivation) and/or to the induction of peripherally induced Tregs (pTregs), previously called induced Tregs (iTregs) in the presence of anti-inflammatory factors (77, 90-92). Both resident and migratory DCs, including pDCs, contribute to this process in the LNs (93-96) (Figure 1B). Nevertheless, emerging evidence demonstrates that peripheral tolerance does not exclusively rely on DCs. Lymph node stromal cells (LNSCs), and in particular LECs, also play an important role in the maintenance of peripheral tolerance (Figure 1B).

\section{PTA-specific Expression by LECs}

The discovery of the ectopic PTA expression by mTECs in the thymus was the first example that cells of non-hematopoietic origin present endogenously expressed self-Ag to T cells $(68,69)$. Using GFAP-HA or iFABP-tOVA transgenic mouse models, in which hemagglutinin (HA) or a truncated form of ovalbumin (tOVA) are expressed as self-Ag in enteric glial cells (EGCs) or mature intestinal epithelial cells (IECs), respectively, it was shown few years ago that the EGC-associated HA or IEC-associated tOVA proteins were unexpectedly expressed not only by EGCs or IECs but also by CD45-negative stromal cells, in all LNs and not exclusively in mesenteric LNs. Those LNSCs were able to process endogenously expressed self-proteins into antigenic peptides to directly present these $\mathrm{Ag}$ to $\mathrm{CD}^{+} \mathrm{T}$ cells in SLOs, making them functionally similar to mTECs in the thymus (97-100). Moreover, it was shown in non-transgenic mouse models that LNSCs naturally express PTAs and directly present them to $\mathrm{CD}^{+} \mathrm{T}$ cells. Among other examples, LNSCs ectopically express tyrosinase (tyr), while its expression is normally confined to melanocytes (101). It was later shown that LECs are the only cells ectopically expressing this $\mathrm{Ag}$ in the $\operatorname{LN}(102,103)$. Indeed, using CD31 and gp38 (Podoplanin) as markers to distinguish the LNSC subtypes, it was observed that each subtype expresses a distinct set of PTAs, with some PTAs exclusively expressed in one specific LNSC subset and some others redundantly expressed $(102,103)$ (Figure 1B). This suggests a non-redundant role for the different LNSC subtypes in the tolerization of various self-specific T cells. In addition, the expression of PTAs by LECs is subanatomically compartmentalized, with a high expression of PTAs observed only in LN medullary sinus LECs (104).
In mTECs, the expression of most, but not all, PTAs is regulated by Aire $(70,71)$. In the $\mathrm{LN}$, a rare bone marrowderived population was described to express Aire and was called extrathymic Aire-expressing cells (eTACs). Consequently, eTACs express various PTAs in an Aire-dependent manner, and present them through major histocompatibility complex class I (MHC-I) and MHC-II molecules to induce CD8 ${ }^{+} \mathrm{T}$ cell deletion (105), and CD4 ${ }^{+} \mathrm{T}$ cell anergy (106), respectively (Figure 1B). On the contrary, PTAs expressed by non-hematopoietic LNSCs, including LECs, are not dependent on Aire (103). The regulation of the expression of the pancreatic self-Ag Ppy by LECs in pancreatic LNs depends on the transcriptional regulator Deaf1, which, together with Aire, belongs to the SAND gene family $(107,108)$. Interestingly, variant isoforms of Deaf1 in mice and human display an impaired Ppy expression, and were linked to autoimmune type I diabetes (107). The fact that LNSCs do not express Aire may explain the low overlapping PTA expression in mTECs and LNSCs (109), therefore suggesting a complementary contribution of mTECs and LNSCs in T cell tolerance induction and maintenance. Future investigations will identify other transcription factors, selectively or commonly expressed by LNSC subsets, which promote different PTA expression.

\section{PTA Presentation by LECs to T Cells}

LNSCs not only endogenously express PTAs but also the direct presentation of PTA-derived peptides in the context of MHC-I molecules to $\mathrm{CD}^{+} \mathrm{T}$ cells leads to their clonal deletion and subsequent tolerance induction $(97,98,101)$ (Figure 1B). In the GFAP-HA or iFABP-tOVA models mentioned above, the lack of presentation of HA or tOVA by enteric stromal cells to HA- or tOVA-specific CD8 ${ }^{+} \mathrm{T}$ cells was associated with enteric autoimmunity. Among other LNSC subsets, LECs are involved in this $\mathrm{CD}^{+} \mathrm{T}$ cell deletional tolerance and are necessary and sufficient for the induction of peripheral tolerance to some selfAg, like Tyr, an autoantigen associated with autoimmune vitiligo $(102,103,107)$. These studies show a crucial role for LECs in the maintenance of peripheral tolerance.

Nevertheless, the ability of LNSCs, and in particular LECs, to directly present endogenously expressed PTAs in the context of MHC-II molecules to $\mathrm{CD}^{+}{ }^{+} \mathrm{T}$ cells is still a matter of debate, as well as the subsequent impact on $\mathrm{CD}^{+} \mathrm{T}$ cell outcome. We have previously shown that the endogenous expression of MHC-II molecules is regulated in LECs, BECs, and FRCs by the promoter IV (pIV) of the master regulator CIITA (110). One study has however demonstrated that the adoptive transfer of HA-specific TCR transgenic $\mathrm{CD}^{+} \mathrm{T}$ cells (6.5) in GFAP-HA transgenic mice, in which HA is expressed as an autoantigen by EGCs, did not dampen lethal enteric autoimmunity (98). However, as mentioned by the authors, the absence of direct presentation of HA peptide by LNSCs to HA-specific $\mathrm{CD}^{+}{ }^{+} \mathrm{T}$ cells in their model does not rule out a possible upregulation of MHC-II molecules in LNSCs and a direct presentation under pro-inflammatory conditions (98). Indeed, several studies that will be discussed later in this review have suggested that LNSCs, among which LECs, upregulate MHC-II molecules at their surface upon inflammation $(110,111)$. 
For their part, Engelhard and colleagues claim that LECs are unable to present endogenously expressed PTAs ( $\beta$-galactosidase, membrane-bound HA or I-E $\alpha$ in their models) to $\mathrm{CD} 4^{+} \mathrm{T}$ cells, not related to Ag localization but due to a lack of H2-M expression in LECs, which would prevent the loading of peptides onto MHC-II molecules (45). However, this study was carried out in the steady state, whereas LECs, BECs, and FRCs, that express IFN- $\gamma$ inducible-CIITA pIV, might require IFN- $\gamma$ to upregulate $\mathrm{H}-2 \mathrm{M}$ molecules, as they do for MHC-II expression, these two genes being co-regulated by CIITA (112). Moreover, Mebius and colleagues observed the presence of mRNA transcripts for $\mathrm{H} 2-\mathrm{M}$ in LECs, among other MHC-II-related molecules (113).

Mebius and colleagues identified that in transgenic mice expressing OVA under the control of the keratin 14 promoter (K14mOVA mice), OVA was unexpectedly expressed in LECs. In addition, $\mathrm{OVA}^{+}$LEC were able to present OVA peptides through MHC-II to OTII cells in vitro, leading to an increased Foxp $3^{+}$ OT-II cells Treg homeostasis (113). Using LN transplantation experiments, the authors further suggested that the presentation of endogenously expressed self-Ag by LNSCs, and especially by LECs, contribute in vivo to the maintenance of Foxp $3^{+} \mathrm{CD}^{+}$ Tregs in the periphery (Figure 1B) (113). Finally, lentiviral vectors allowing the selective transduction of $\mathrm{MHC}-\mathrm{II}^{+}$nonhematopoietic cells with MHC-II- and MHC-I-restricted HY male-derived epitopes induced $\mathrm{T}$ cell hyporesponsiveness/ anergy of HY-specific $\mathrm{CD}^{+}$and $\mathrm{CD}^{+} \mathrm{T}$ cells in female mice (114). Moreover, in Marilyn TCR transgenic mice expressing HY-specific $\mathrm{CD}^{+} \mathrm{T}$ cells, increased conversion of effector $\mathrm{CD}^{+} \mathrm{T}$ cells into CD25 ${ }^{+}$Foxp $3^{+}$pTregs was observed (114). Whether these effects were due to a direct Ag presentation of endogenously expressed $\mathrm{HY}$ to $\mathrm{CD} 4^{+} \mathrm{T}$ cells by gp $38^{+}$stromal cells, i.e., LECs and FRCs in the LN, remains to be determined. Indeed, as stated by the authors, they cannot rule out that other, non-DC, hematopoietic cell types could contribute to the presentation of HY Ags, due to undesired transduction and subsequent direct Ag presentation and/or Ag transfer to stromal cells (110, 114). Despite a lack of demonstration of direct Ag presentation by gp $38^{+}$stromal cells and the lack of distinction between the contribution of the different stromal cell subtypes in this model, these data are in accordance with the results of Baptista et al., as mentioned above (113).

\section{Molecular Pathways Involved in LEC-Mediated Peripheral T Cell Tolerance}

The molecular pathways involved in the clonal deletion of $\mathrm{CD}^{+} \mathrm{T}$ cells by LNSCs, and in particular by LECs, are not fully elucidated. Using the iFABP-tOVA transgenic mouse model described above, in which tOVA is expressed as a self-Ag in the intestinal epithelium, it was shown that the induction of $\mathrm{CD}^{+} \mathrm{T}$ cell tolerance requires $\mathrm{PD}-1: \mathrm{PD}-\mathrm{L} 1$ interaction, as the disruption of this pathway leads to severe intestinal enteric autoimmune disorder (115). More specifically, in a model of adoptive transfer of Tyr-specific TCR transgenic CD8 ${ }^{+} \mathrm{T}$ cells (FH T cells) into Tyr-expressing bone marrow chimeric mice, in which either radiosensitive hematopoietic or radioresistant non-hematopoietic cells lacked PD-L1 expression, FH T cells were deleted only when PD-L1 was expressed by the nonhematopoietic LN compartment (116). Moreover, among the LNSC subsets, LECs were the ones expressing the highest level of PD-L1, with medullary sinuses LECs being the highest expressers. In addition, LECs do not express costimulatory molecules at their surface. The administration of agonistic anti-4-1BB antibodies prevented the deletion of $\mathrm{FH} \mathrm{CD} 8^{+} \mathrm{T}$ cells. The lack of costimulation through 4-1BB by LECs would lead to PD-1 upregulation by FH T cells, as Tyr presentation by LECs led to a higher expression of PD-1 by FH T cells, an effect that was suppressed upon agonistic anti-4-1BB antibody administration. This would, in turn, prevent CD25 upregulation, which is necessary for $\mathrm{CD}^{+} \mathrm{T}$ cells survival. Indeed, CD25 expression on $\mathrm{FH}$ $\mathrm{T}$ cells was upregulated only in the presence of agonistic anti-41BB or blocking anti-PD-L1 antibodies after Tyr presentation by LECs (116). Hence, in this model, LECs are responsible for the presentation of the endogenously expressed Tyr, which, together with a combination of a lack of costimulation and a provision of co-inhibitory signal, leads to Tyr-specific $\mathrm{CD}^{+} \mathrm{T}$ cell deletion (116). The high expression of PD-L1 in LECs is likely regulated by lymphotoxin $\beta$ receptor ( $\mathrm{Lt} \beta \mathrm{r}$ ), as the treatment of mice with anti-Lt $\beta \mathrm{r}$ antibodies led to decreased PD-L1 expression in LECs (104). Using $\mu \mathrm{MT}^{-/-}, \mathrm{CD} 3 \varepsilon^{-/-}$, and $\mathrm{Rag} 1^{-/-}$mice, it was further shown that $B$ cells are required for the expression of the adhesion molecule MadCAM-1 at the surface of LECs in the medulla, itself necessary for the expression of PD-L1. On the contrary, T cells seemed to suppress PD-L1 expression in LECs through mechanisms that have not been deciphered yet (104). Finally, it was suggested that the expression of MHC-II on LECs would be involved in the induction of $\mathrm{CD}^{+} \mathrm{T}$ cells tolerance to endogenously expressed self-Ag in LECs by engaging the inhibitory molecule LAG-3. Indeed, after adoptive transfer of $\beta$-gal-specific TCR transgenic CD ${ }^{+} \mathrm{T}$ cells (Bg1 cells) into Prox-1x $\beta$ gal mice, in which $\beta$-gal is selectively expressed by LECs, the proliferation of Bg1 cells was increased following administration of blocking anti-LAG-3 antibodies, which was acting in synergy with antiPD-L1 blocking antibodies (45).

We previously showed that high PD-L1 expression by LECs correlate with their unique ability, compared to other LNSC subsets, to induce $\mathrm{CD} 4^{+} \mathrm{T}$ cell apoptosis after presentation of DC-acquired peptide-MHC-II complexes (110). Although the molecular mechanisms accounting for the induction of tolerance to MHC-II-restricted self-Ag endogenously expressed and directly presented by LECs to $\mathrm{CD} 4^{+} \mathrm{T}$ cells have not been elucidated so far, they are thus likely to involve PD-L1 expression by LECs, as in the case of $\mathrm{CD} 8^{+} \mathrm{T}$ cells.

\section{Ag Acquisition and Presentation by LECs to T Cells}

The lymphatic system, by controlling Ag availability, constitutes one of the first checkpoints for immune responses (100). It is not surprising then that LECs, which have early access to any given $\mathrm{Ag}$, display different mechanisms for $\mathrm{Ag}$ uptake and processing (Figure 2). Indeed, recent work revealed that $\mathrm{Ag}$ trafficking can be observed at more levels than the classical concept of LECs as lymph carriers. Complex interactions between 


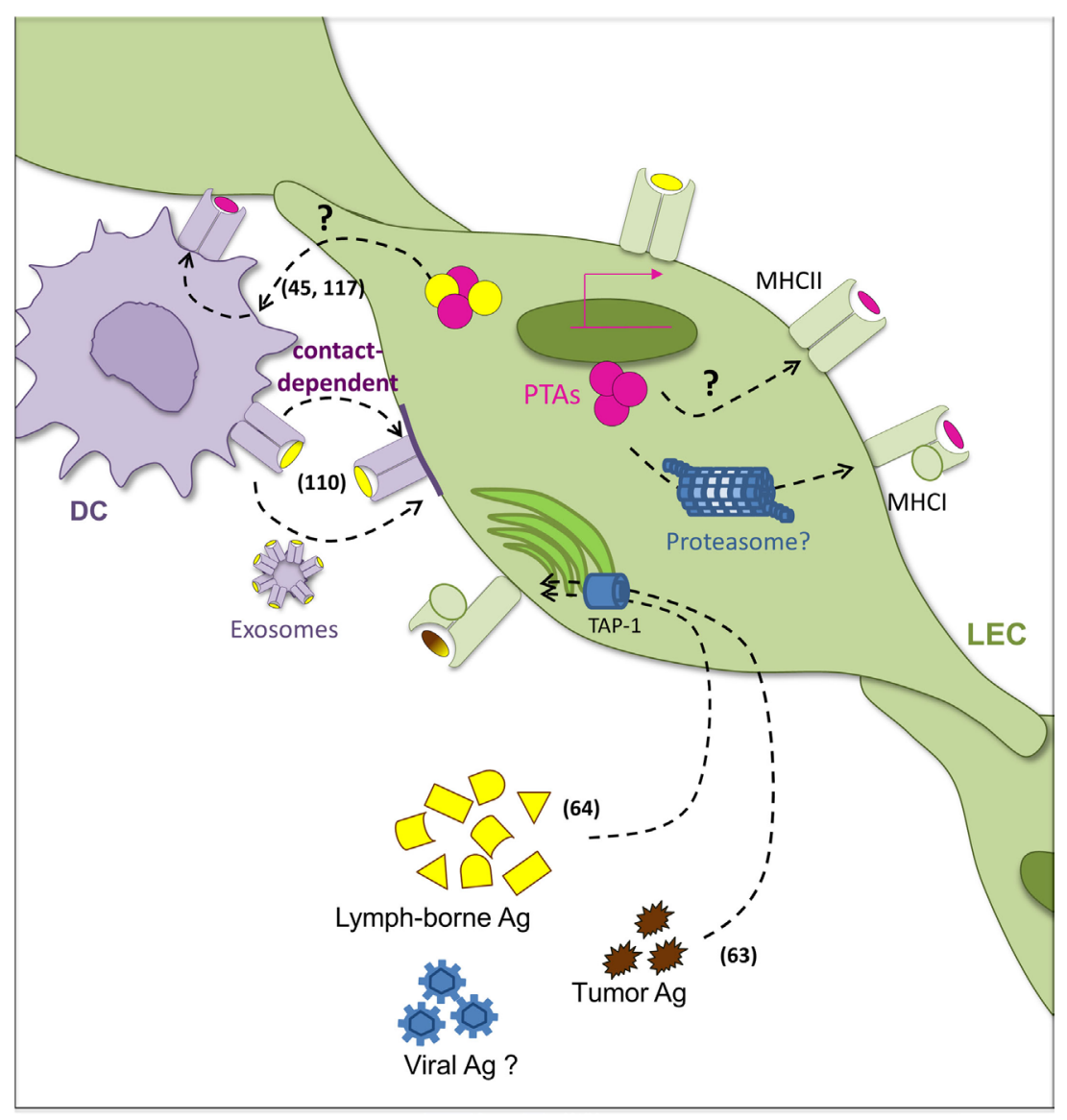

FIGURE 2 | Pathways of Ag acquisition and presentation by LECs. Several pathways of antigen (Ag) acquisition and loading coexist in lymphatic endothelial cells (LECs). Interactions with dendritic cells (DCs) underlie complex mechanisms of Ag transfer in both directions. On one hand, LECs act as Ag reservoirs for DCs which can uptake LEC-derived Ag. The mechanisms accounting for this phenomenon remain however unclear. On the other hand, LECs acquire peptide-MHC-II complexes from DCs in a cell-cell contact dependent manner (DC-derived Ag is depicted in yellow). DC-derived exosomes might also be implicated. Peripheral tissue-restricted Ags (PTA) (in pink) expressed by LEC can be loaded into MHC-I molecules. Intracellular pathways of degradation of such PTAs have however been not investigated. Moreover, whether PTA can be incorporated in MHC-II compartments is still a matter of debate. Alternatively, LECs possess the ability to uptake exogenous lymph-borne and tumor-derived Ag that can be incorporated in MHC-I pathway in a TAP-1-dependent manner. Related references are indicated in numbers.

LECs and DCs $(45,110,117)$ depict an exciting picture of Ag bidirectional exchange that ultimately may serve to modulate the overall magnitude of the immune response (Figure 2).

\section{Uptake of Exogenous Ag}

It has been extensively demonstrated in several mouse and human models that LECs exhibit an active endocytotic capacity $(38,118)$. They are able to uptake exogenous molecules and, depending on their location, process Ag for cross-presentation and cross-priming of Ag-specific CD8 ${ }^{+} \mathrm{T}$ cells $(63,64)$ (Figure 2). Interestingly, Ag-loaded primary LN LECs were shown to be capable of cross-priming Ag-specific $\mathrm{CD}^{+} \mathrm{T}$ cells in a TAP1dependent manner (64). As described above for endogenous PTA presentation, Ag-loaded LECs induced T cell apoptosis, the lack of expression of costimulatory molecules being the most extended explanation. LECs neither express nor upregulate the costimulatory molecules CD40, CD80, and CD86 following TLR engagement or in presence of IFN- $\gamma$ or TNF- $\alpha(110,116)$. While
LECs upregulate the immunostimulatory molecules HVEM, CD48, and MHC-II under such conditions (116), they also upregulate PD-L1 $(102,110,119)$. Pointing at the same direction, Ag cross-presentation by LSECs induces tolerized $\mathrm{CD}^{+} \mathrm{T}$ cells in the liver. In this context, PD-L1 expression was also relevant for such outcome (120). Interestingly, in the absence of inflammation, surviving LSEC-educated T cells had an Ag-experienced central memory-like phenotype in SLOs (121). Furthermore, LSEC-primed memory $\mathrm{T}$ cells could be reactivated in vitro and in vivo in an Ag-specific manner, and they could contribute to a viral challenge (121).

The direct contribution of Ag presentation by LECs to $\mathrm{CD}^{+}$viral immunity is still a matter of debate. As mentioned above, LECs serve as Ag reservoir during viral infections (117) (Figure 2). Nonetheless, genetic ablation of MHC-II in radioresistant stromal cells in LNs resulted in longer maintenance of Ag-specific CD4 ${ }^{+}$T cells (122). Specific impact of LN LECs and mechanisms accounting for such effects should be yet clarified. 


\section{Cellular Ag Transfer}

The hallmark of professional APCs is the constitutive cell surface presence of MHC-II and their ability for Ag processing and presentation (123). Constitutive MHC-II expression is restricted to a small number of cells of the immune system. Nonetheless, there are many different cell types from both hematopoietic and non-hematopoietic origins that can indeed express MHC-II and interact with CD4 ${ }^{+} \mathrm{T}$ cells in the periphery $(100,124,125)$.

As mentioned above, LECs constitute such non-professional APC cell types that express MHC-II in an IFN- $\gamma$-dependent manner. Indeed, MHC-II expression in LN LECs has been reported at both transcriptional and protein expression levels $(102,110,111)$. By using transgenic mouse models lacking the different CIITA promoters, we have previously demonstrated that steady-state levels of MHC-II molecules on the surface of LECs and other stromal subsets in LNs reflect a combination of IFN- $\gamma$-inducible basal activity and acquired peptide:MHC-II complexes from DCs (110). The acquired MHC-II molecules were loaded with DC-derived Ags, licensing LECs to induce anergy and increased cell death Ag-specific CD4 ${ }^{+} \mathrm{T}$ cells (Figures $1 \mathrm{~B}$ and 2). Lack of measurable productive $\mathrm{T}$ cell responses has been one of the major difficulties preventing the clarification of the impact of Ag presentation by LECs on $\mathrm{CD} 4^{+} \mathrm{T}$ cell outcome. As for $\mathrm{CD}^{+}$ $\mathrm{T}$ cell responses, the absence of costimulatory signals, such as CD80 or CD86 and the constitutive expression of PD-L1 by LECs, preclude the possibility of functional effector $\mathrm{CD} 4^{+} \mathrm{T}$ cell priming. In this regard, it has been shown that human LN-derived LECs fail to induce allogeneic $\mathrm{CD} 4^{+} \mathrm{T}$ cell proliferation even after IFN- $\gamma$ stimulation (119). In these particular in vitro settings, LECs were unable to induce proliferation of either naïve or memory $\mathrm{CD} 4^{+} \mathrm{T}$ cells.

Membrane exchange between cells is not uncommon in immunology (126). Peptide:MHC-I and MHC-II complexes have been shown to be transferred between DC and tumor cells (127) or infected cells (128), as well as between DCs (129). Ag transfer can occur as peptide exchange on cell surfaces. Peptide epitopes can bind directly on cell surface or early endosomal MHC molecules (130), where both MHC-I and MHC-II are receptive for lymphborne peptide binding. This might be particularly relevant in the context of self-tolerance, since recent analyses showed that the human lymph peptidome contains predominantly self-peptides, including products derived from extracellular processing of proteins (131). Exosomes were also implicated in the transfer of peptide:MHC-II complexes from DCs to LNSCs (110), and they cannot be excluded to contribute to alternative Ag trafficking (Figure 2).

Antigen transfer between LECs and DCs is, however, not restricted to one direction. Indeed, the transfer of PTAs specifically expressed in LECs to hematopoietic cells has been described (45) (Figure 2). Neither membrane-bound nor cytoplasmic PTAs were directly presented by LECs to prime Ag-specific $\mathrm{CD}^{+} \mathrm{T}$ cell responses. As mentioned above, this was attributed to the lower expression of H2-M in LECs compared to professional APCs, which is required for peptide binding into the MHC-II groove. Instead, peptides derived from PTAs expressed by LECs were found to be loaded onto MHC-II in DCs (45). While the exchange mechanism is still open to examination, it was reported not to be dependent on recognition of apoptotic cells or DC phagocytosis. These complementary bidirectional observations highlight the close relationship and communication between professional APCs and LECs to enable MHC-II presentation.

\section{CONCLUDING REMARKS}

Increasing evidence suggest that lymphatics are much more than simple pipes that drain tissue-derived fluids containing proteins, particles, and cells. Through the expression of different surface molecules and the production of soluble factors, LECs indeed modulate immune responses in many ways, including the active regulation of cellular migration, interactions, and functions. Recent studies have highlighted a possible role for LECs as direct instructors of $\mathrm{T}$ cell immunity. Indeed, the discovery that LNSCs, including LECs, ectopically express tissue-derived Ags, a feature thought to be restricted to mTECs and thymic central $\mathrm{T}$ cell tolerance, has pushed forward LECs to potentially function as Ag-presenting cells. Accordingly, the selective expression of model Ags in LECs leads to an Ag-specific recognition by T cells, which, after an early step of activation and proliferation, are either inactivated or deleted. Therefore, the presentation of endogenously expressed Ags by LECs seems to contribute to peripheral T cell tolerance. Studies have also suggested that LECs acquire exogenous Ags by distinct pathways, including direct uptake, or cell-membrane transfer, and present them to induce $\mathrm{T}$ cell dysfunction. The molecular mechanisms contributing to LEC ability to inactivate $\mathrm{T}$ cells are still not fully elucidated. However, a consensus candidate, PD-L1, the ligand for programcell death 1 receptor expressed by T cells, emerged from several recent studies to be highly expressed by LECs, and important to mediate $\mathrm{T}$ cell tolerance. Although pioneering studies suggest that Ag-presenting LNSCs are sufficient to maintain peripheral T cell tolerance, the specific contribution of LECs remains to be addressed. Likewise, substantial differences among LECs from distinct anatomical locations entail different functions. Specific roles of local LECs should be carefully dissected in order to fully understand how they differentially impact $\mathrm{T}$ cell responses. In addition, most studies so far have been performed in steady state, and the contribution of Ag presentation by LECs under different pathological conditions in shaping of peripheral $\mathrm{T}$ cell responses remains to be determined. In addition, future studies will assess how current therapies for cancer or autoimmune diseases aiming at modulating immune cell functions, specifically alter the ability of LECs to impact $\mathrm{T}$ cell responses.

\section{AUTHOR CONTRIBUTIONS}

SH, JD, and $\mathrm{MH}$ have developed the concept, wrote the manuscript, prepared the figures, and critically read, revised, and approved the manuscript.

\section{FUNDING}

SH's laboratory is supported by the Swiss National Science Foundation (310030_166541), the European Research Council (281365), and the Swiss MS Society. 


\section{REFERENCES}

1. Asellius G. De Lactibus Sive Lacteis Venis. Milan: Mediolani (1627).

2. Witte MH, Bernas MJ, Martin CP, Witte CL. Lymphangiogenesis and lymphangiodysplasia: from molecular to clinical lymphology. Microsc Res Tech (2001) 55(2):122-45. doi:10.1002/jemt.1163.abs

3. Nicenboim J, Malkinson G, Lupo T, Asaf L, Sela Y, Mayseless O, et al. Lymphatic vessels arise from specialized angioblasts within a venous niche. Nature (2015) 522(7554):56-61. doi:10.1038/nature14425

4. Choi I, Lee S, Hong YK. The new era of the lymphatic system: no longer secondary to the blood vascular system. Cold Spring Harb Perspect Med (2012) 2(4):a006445. doi:10.1101/cshperspect.a006445

5. Huntington GSM, McClure CFW. The anatomy and development of the jugular lymph sac in the domestic cat (Felis domestica). Am J Anat (1910) (10):177-311.

6. Sabin FR. On the origin of the lymphatic system from the veins and the development of the lymph hearts and thoracic duct in the pig. Am J Anat (1902) 1:367-691. doi:10.1002/aja.1000010310

7. Sabin FR. On the development of the superficial lymphatics in the skin of the pig. Am J Anat (1904) 3(2):183-95. doi:10.1002/aja.1000030205

8. Kaipainen A, Korhonen J, Mustonen T, van Hinsbergh VW, Fang GH, Dumont D, et al. Expression of the FMS-like tyrosine kinase 4 gene becomes restricted to lymphatic endothelium during development. Proc Natl Acad Sci U S A (1995) 92(8):3566-70. doi:10.1073/pnas.92.8.3566

9. Oliver G. Lymphatic vasculature development. Nat Rev Immunol (2004) 4(1):35-45. doi:10.1038/nri1258

10. Wigle JT, Harvey N, Detmar M, Lagutina I, Grosveld G, Gunn MD, et al. An essential role for Prox 1 in the induction of the lymphatic endothelial cell phenotype. EMBO J (2002) 21(7):1505-13. doi:10.1093/emboj/21.7.1505

11. Dumont DJ, Jussila L, Taipale J, Lymboussaki A, Mustonen T, Pajusola K, et al. Cardiovascular failure in mouse embryos deficient in VEGF receptor-3. Science (1998) 282(5390):946-9. doi:10.1126/science.282.5390.946

12. Kukk E, Lymboussaki A, Taira S, Kaipainen A, Jeltsch M, Joukov V, et al. VEGF-C receptor binding and pattern of expression with VEGFR-3 suggests a role in lymphatic vascular development. Development (1996) 122(12):3829-37.

13. Saaristo A, Veikkola T, Tammela T, Enholm B, Karkkainen MJ, Pajusola $\mathrm{K}$, et al. Lymphangiogenic gene therapy with minimal blood vascular side effects. J Exp Med (2002) 196(6):719-30. doi:10.1084/jem.20020587

14. Jeltsch M, Kaipainen A, Joukov V, Meng X, Lakso M, Rauvala H, et al. Hyperplasia of lymphatic vessels in VEGF-C transgenic mice. Science (1997) 276(5317):1423-5. doi:10.1126/science.276.5317.1423

15. Wigle JT, Oliver G. Proxl function is required for the development of the murine lymphatic system. Cell (1999) 98(6):769-78. doi:10.1016/ S0092-8674(00)81511-1

16. Petrova TV, Mäkinen T, Mäkelä TP, Saarela J, Virtanen I, Ferrell RE, et al. Lymphatic endothelial reprogramming of vascular endothelial cells by the Prox-1 homeobox transcription factor. EMBO J (2002) 21(17):4593-9. doi:10.1093/emboj/cdf470

17. Hirakawa S, Hong YK, Harvey N, Schacht V, Matsuda K, Libermann T, et al. Identification of vascular lineage-specific genes by transcriptional profiling of isolated blood vascular and lymphatic endothelial cells. Am J Pathol (2003) 162(2):575-86. doi:10.1016/S0002-9440(10)63851-5

18. Podgrabinska S, Braun P, Velasco P, Kloos B, Pepper MS, Skobe M. Molecular characterization of lymphatic endothelial cells. Proc Natl Acad Sci U S A (2002) 99(25):16069-74. doi:10.1073/pnas.242401399

19. Johnson NC, Dillard ME, Baluk P, McDonald DM, Harvey NL, Frase SL, et al. Lymphatic endothelial cell identity is reversible and its maintenance requires Proxl activity. Genes Dev (2008) 22(23):3282-91. doi:10.1101/ gad.1727208

20. Yaniv K, Isogai S, Castranova D, Dye L, Hitomi J, Weinstein BM, et al. Live imaging of lymphatic development in the zebrafish. Nat Med (2006) 12(6):711-6. doi:10.1038/nm1427

21. Klotz L, Norman S, Vieira JM, Masters M, Rohling M, Dubé KN, et al. Cardiac lymphatics are heterogeneous in origin and respond to injury. Nature (2015) 522(7554):62-7. doi:10.1038/nature 14483

22. Alitalo K, Tammela T, Petrova TV. Lymphangiogenesis in development and human disease. Nature (2005) 438(7070):946-53. doi:10.1038/nature04480
23. Baluk P, Fuxe J, Hashizume H, Romano T, Lashnits E, Butz S, et al. Functionally specialized junctions between endothelial cells of lymphatic vessels. J Exp Med (2007) 204(10):2349-62. doi:10.1084/jem.20062596

24. Tammela T, Saaristo A, Holopainen T, Lyytikkä J, Kotronen A, Pitkonen M, et al. Therapeutic differentiation and maturation of lymphatic vessels after lymph node dissection and transplantation. Nat Med (2007) 13(12):1458-66. doi: $10.1038 / \mathrm{nm} 1689$

25. Friedlaender $\mathrm{MH}$, Chisari FV, Baer $\mathrm{H}$. The role of the inflammatory response of skin and lymph nodes in the induction of sensitization to simple chemicals. J Immunol (1973) 111(1):164-70.

26. Thomas SN, Rutkowski JM, Pasquier M, Kuan EL, Alitalo K, Randolph GJ, et al. Impaired humoral immunity and tolerance in K14-VEGFR-3-Ig mice that lack dermal lymphatic drainage. J Immunol (2012) 189(5):2181-90. doi:10.4049/jimmunol.1103545

27. Wisse E. An electron microscopic study of the fenestrated endothelial lining of rat liver sinusoids. J Ultrastruct Res (1970) 31(1):125-50. doi:10.1016/ S0022-5320(70)90150-4

28. Limmer A, Ohl J, Kurts C, Ljunggren HG, Reiss Y, Groettrup M, et al. Efficient presentation of exogenous antigen by liver endothelial cells to CD8+ T cells results in antigen-specific T-cell tolerance. Nat Med (2000) 6(12):1348-54. doi: $10.1038 / 82161$

29. Mohammad MG, Tsai VW, Ruitenberg MJ, Hassanpour M, Li H, Hart PH, et al. Immune cell trafficking from the brain maintains CNS immune tolerance. J Clin Invest (2014) 124(3):1228-41. doi:10.1172/JCI71544

30. Louveau A, Smirnov I, Keyes TJ, Eccles JD, Rouhani SJ, Peske JD, et al. Structural and functional features of central nervous system lymphatic vessels. Nature (2015) 523(7560):337-41. doi:10.1038/nature14432

31. Cupovic J, Onder L, Gil-Cruz C, Weiler E, Caviezel-Firner S, Perez-Shibayama C, et al. Central Nervous system stromal cells control local CD8(+) T cell responses during virus-induced neuroinflammation. Immunity (2016) 44(3):622-33. doi:10.1016/j.immuni.2015.12.022

32. Leong SP, Nakakura EK, Pollock R, Choti MA, Morton DL, Henner WD, et al. Unique patterns of metastases in common and rare types of malignancy. J Surg Oncol (2011) 103(6):607-14. doi:10.1002/jso.21841

33. Stacker SA, Williams SP, Karnezis T, Shayan R, Fox SB, Achen MG. Lymphangiogenesis and lymphatic vessel remodelling in cancer. Nat Rev Cancer (2014) 14(3):159-72. doi:10.1038/nrc3677

34. Dieterich LC, Detmar M. Tumor lymphangiogenesis and new drug development. Adv Drug Deliv Rev (2016) 99(Pt B):148-60. doi:10.1016/ j.addr.2015.12.011

35. Moon JJ, Chu HH, Pepper M, McSorley SJ, Jameson SC, Kedl RM, et al. Naive CD4(+) T cell frequency varies for different epitopes and predicts repertoire diversity and response magnitude. Immunity (2007) 27(2):203-13. doi:10.1016/j.immuni.2007.07.007

36. Obar JJ, Khanna KM, Lefrancois L. Endogenous naive CD8+ T cell precursor frequency regulates primary and memory responses to infection. Immunity (2008) 28(6):859-69. doi:10.1016/j.immuni.2008.04.010

37. Roozendaal R, Mempel TR, Pitcher LA, Gonzalez SF, Verschoor A, Mebius RE, et al. Conduits mediate transport of low-molecular-weight antigen to lymph node follicles. Immunity (2009) 30(2):264-76. doi:10.1016/ j.immuni.2008.12.014

38. Sixt M, Kanazawa N, Selg M, Samson T, Roos G, Reinhardt DP, et al. The conduit system transports soluble antigens from the afferent lymph to resident dendritic cells in the $\mathrm{T}$ cell area of the lymph node. Immunity (2005) 22(1):19-29. doi:10.1016/j.immuni.2004.11.013

39. Gerner MY, Torabi-Parizi P, Germain RN. Strategically localized dendritic cells promote rapid $\mathrm{T}$ cell responses to lymph-borne particulate antigens. Immunity (2015) 42(1):172-85. doi:10.1016/j.immuni. 2014.12.024

40. Pflicke H, Sixt M. Preformed portals facilitate dendritic cell entry into afferent lymphatic vessels. J Exp Med (2009) 206(13):2925-35. doi:10.1084/ jem.20091739

41. Lämmermann T, Bader BL, Monkley SJ, Worbs T, Wedlich-Söldner R, Hirsch K, et al. Rapid leukocyte migration by integrin-independent flowing and squeezing. Nature (2008) 453(7191):51-5. doi:10.1038/ nature 06887

42. Johnson LA, Clasper S, Holt AP, Lalor PF, Baban D, Jackson DG. An inflammation-induced mechanism for leukocyte transmigration across lymphatic 
vessel endothelium. JExp Med (2006) 203(12):2763-77. doi:10.1084/ jem.20051759

43. Acton SE, Astarita JL, Malhotra D, Lukacs-Kornek V, Franz B, Hess PR, et al. Podoplanin-rich stromal networks induce dendritic cell motility via activation of the C-type lectin receptor CLEC-2. Immunity (2012) 37(2):276-89. doi:10.1016/j.immuni.2012.05.022

44. Podgrabinska S, Kamalu O, Mayer L, Shimaoka M, Snoeck H, Randolph GJ, et al. Inflamed lymphatic endothelium suppresses dendritic cell maturation and function via Mac-1/ICAM-1-dependent mechanism. J Immunol (2009) 183(3):1767-79. doi:10.4049/jimmunol.0802167

45. Rouhani SJ, Eccles JD, Riccardi P, Peske JD, Tewalt EF, Cohen JN, et al. Roles of lymphatic endothelial cells expressing peripheral tissue antigens in CD4 T-cell tolerance induction. Nat Commun (2015) 6:6771. doi:10.1038/ ncomms 7771

46. Luther SA, Bidgol A, Hargreaves DC, Schmidt A, Xu Y, Paniyadi J, et al. Differing activities of homeostatic chemokines CCL19, CCL21, and CXCL12 in lymphocyte and dendritic cell recruitment and lymphoid neogenesis. J Immunol (2002) 169(1):424-33. doi:10.4049/jimmunol. 169.1.424

47. Link A, Vogt TK, Favre S, Britschgi MR, Acha-Orbea H, Hinz B, et al. Fibroblastic reticular cells in lymph nodes regulate the homeostasis of naive T cells. Nat Immunol (2007) 8(11):1255-65. doi:10.1038/ni1513

48. Hara T, Shitara S, Imai K, Miyachi H, Kitano S, Yao H, et al. Identification of IL-7-producing cells in primary and secondary lymphoid organs using IL-7-GFP knock-in mice. J Immunol (2012) 189(4):1577-84. doi:10.4049/ jimmunol.1200586

49. Miller CN, Hartigan-O'Connor DJ, Lee MS, Laidlaw G, Cornelissen IP, Matloubian M, et al. IL-7 production in murine lymphatic endothelial cells and induction in the setting of peripheral lymphopenia. Int Immunol (2013) 25(8):471-83. doi:10.1093/intimm/dxt012

50. Onder L, Narang P, Scandella E, Chai Q, Iolyeva M, Hoorweg K, et al. IL-7producing stromal cells are critical for lymph node remodeling. Blood (2012) 120(24):4675-83. doi:10.1182/blood-2012-03-416859

51. Iolyeva $M$, Aebischer D, Proulx ST, Willrodt AH, Ecoiffier T, Häner S, et al. Interleukin-7 is produced by afferent lymphatic vessels and supports lymphatic drainage. Blood (2013) 122(13):2271-81. doi:10.1182/blood2013-01-478073

52. Schluns KS, Kieper WC, Jameson SC, Lefrancois L. Interleukin-7 mediates the homeostasis of naive and memory CD8 T cells in vivo. Nat Immunol (2000) 1(5):426-32. doi:10.1038/80868

53. Schluns KS, Lefrancois L. Cytokine control of memory T-cell development and survival. Nat Rev Immunol (2003) 3(4):269-79. doi:10.1038/ nri1052

54. Pham TH, Baluk P, Xu Y, Grigorova I, Bankovich AJ, Pappu R, et al. Lymphatic endothelial cell sphingosine kinase activity is required for lymphocyte egress and lymphatic patterning. J Exp Med (2010) 207(1):17-27. doi:10.1084/ jem.20091619

55. Grigorova IL, Schwab SR, Phan TG, Pham TH, Okada T, Cyster JG. Cortical sinus probing, S1P1-dependent entry and flow-based capture of egressing T cells. Nat Immunol (2009) 10(1):58-65. doi:10.1038/ni.1682

56. Pham TH, Okada T, Matloubian M, Lo CG, Cyster JG. S1P1 receptor signaling overrides retention mediated by $\mathrm{G}$ alpha I-coupled receptors to promote $\mathrm{T}$ cell egress. Immunity (2008) 28(1):122-33. doi:10.1016/ j.immuni.2007.11.017

57. Swartz MA, Lund AW. Lymphatic and interstitial flow in the tumour microenvironment: linking mechanobiology with immunity. Nat Rev Cancer (2012) 12(3):210-9. doi:10.1038/nrc3186

58. Roberts EW, Broz ML, Binnewies M, Headley MB, Nelson AE, Wolf DM, et al. Critical role for CD103(+)/CD141(+) dendritic cells bearing CCR7 for tumor antigen trafficking and priming of $\mathrm{T}$ cell immunity in melanoma. Cancer Cell (2016) 30(2):324-36. doi:10.1016/j.ccell.2016.06.003

59. Galon J, Costes A, Sanchez-Cabo F, Kirilovsky A, Mlecnik B, LagorcePages C, et al. Type, density, and location of immune cells within human colorectal tumors predict clinical outcome. Science (2006) 313(5795):1960-4. doi:10.1126/science.1129139

60. Fridman WH, Pagès F, Sautès-Fridman $\mathrm{C}$, Galon J. The immune contexture in human tumours: impact on clinical outcome. Nat Rev Cancer (2012) 12(4):298-306. doi:10.1038/nrc3245
61. Shields JD, Kourtis IC, Tomei AA, Roberts JM, Swartz MA. Induction of lymphoidlike stroma and immune escape by tumors that express the chemokine CCL21. Science (2010) 328(5979):749-52. doi:10.1126/ science. 1185837

62. Thompson ED, Enriquez HL, Fu YX, Engelhard VH. Tumor masses support naive $\mathrm{T}$ cell infiltration, activation, and differentiation into effectors. J Exp Med (2010) 207(8):1791-804. doi:10.1084/jem.20092454

63. Lund AW, Duraes FV, Hirosue S, Raghavan VR, Nembrini C, Thomas SN, et al. VEGF-C promotes immune tolerance in B16 melanomas and cross-presentation of tumor antigen by lymph node lymphatics. Cell Rep (2012) 1(3):191-9. doi:10.1016/j.celrep.2012.01.005

64. Hirosue S, Vokali E, Raghavan VR, Rincon-Restrepo M, Lund AW, Corthésy-Henrioud $\mathrm{P}$, et al. Steady-state antigen scavenging, crosspresentation, and CD8 + T cell priming: a new role for lymphatic endothelial cells. J Immunol (2014) 192(11):5002-11. doi:10.4049/jimmunol.1302492

65. Riedel A, Shorthouse D, Haas L, Hall BA, Shields J. Tumor-induced stromal reprogramming drives lymph node transformation. Nat Immunol (2016) 17(9):1118-27. doi:10.1038/ni.3492

66. Xing Y, Hogquist KA. T-cell tolerance: central and peripheral. Cold Spring Harb Perspect Biol (2012) 4(6). doi:10.1101/cshperspect.a006957

67. Klein L, Kyewski B, Allen PM, Hogquist KA. Positive and negative selection of the T cell repertoire: what thymocytes see (and don't see). Nat Rev Immunol (2014) 14(6):377-91. doi:10.1038/nri3667

68. Kyewski B, Rottinger B, Klein L. Making central T-cell tolerance efficient: thymic stromal cells sample distinct self-antigen pools. Curr Top Microbiol Immunol (2000) 251:139-45.

69. Derbinski J, Schulte A, Kyewski B, Klein L. Promiscuous gene expression in medullary thymic epithelial cells mirrors the peripheral self. Nat Immunol (2001) 2(11):1032-9. doi:10.1038/ni723

70. Derbinski J, Gäbler J, Brors B, Tierling S, Jonnakuty S, Hergenhahn M, et al. Promiscuous gene expression in thymic epithelial cells is regulated at multiple levels. J Exp Med (2005) 202(1):33-45. doi:10.1084/jem.20050471

71. Anderson MS, Venanzi ES, Klein L, Chen Z, Berzins SP, Turley SJ, et al. Projection of an immunological self shadow within the thymus by the Aire protein. Science (2002) 298(5597):1395-401. doi:10.1126/science.1075958

72. Liston A, Gray DH, Lesage S, Fletcher AL, Wilson J, Webster KE, et al. Gene dosage - limiting role of Aire in thymic expression, clonal deletion, and organ-specific autoimmunity. J Exp Med (2004) 200(8):1015-26. doi:10.1084/jem.20040581

73. Gallegos AM, Bevan MJ. Central tolerance to tissue-specific antigens mediated by direct and indirect antigen presentation. J Exp Med (2004) 200(8):1039-49. doi:10.1084/jem.20041457

74. Koble C, Kyewski B. The thymic medulla: a unique microenvironment for intercellular self-antigen transfer. J Exp Med (2009) 206(7):1505-13. doi:10.1084/jem.20082449

75. Bonasio R, Scimone ML, Schaerli P, Grabie N, Lichtman AH, von Andrian UH. Clonal deletion of thymocytes by circulating dendritic cells homing to the thymus. Nat Immunol (2006) 7(10):1092-100. doi:10.1038/ni1106-1234b

76. Hadeiba H, Lahl K, Edalati A, Oderup C, Habtezion A, Pachynski R, et al. Plasmacytoid dendritic cells transport peripheral antigens to the thymus to promote central tolerance. Immunity (2012) 36(3):438-50. doi:10.1016/ j.immuni.2012.01.017

77. Abbas AK, Benoist C, Bluestone JA, Campbell DJ, Ghosh S, Hori S, et al. Regulatory T cells: recommendations to simplify the nomenclature. Nat Immunol (2013) 14(4):307-8. doi:10.1038/ni.2554

78. Cosmi L, Liotta F, Lazzeri E, Francalanci M, Angeli R, Mazzinghi B, et al. Human CD8+CD25+ thymocytes share phenotypic and functional features with CD4+CD25+ regulatory thymocytes. Blood (2003) 102(12):4107-14. doi:10.1182/blood-2003-04-1320

79. Ménager-Marcq I, Pomié C, Romagnoli P, van Meerwijk JP. CD8+CD28regulatory $\mathrm{T}$ lymphocytes prevent experimental inflammatory bowel disease in mice. Gastroenterology (2006) 131(6):1775-85. doi:10.1053/ j.gastro.2006.09.008

80. Vuddamalay Y, Attia M, Vicente R, Pomié C, Enault G, Leobon B, et al. Mouse and human CD8(+) CD28(low) regulatory T lymphocytes differentiate in the thymus. Immunology (2016) 148(2):187-96. doi:10.1111/ imm. 12600 
81. Pomie C, Menager-Marcq I, van Meerwijk JP. Murine CD8+ regulatory T lymphocytes: the new era. Hum Immunol (2008) 69(11):708-14. doi:10.1016/j.humimm.2008.08.288

82. Lohse AW, Dinkelmann M, Kimmig M, Herkel J, Meyer zum Büschenfelde $\mathrm{KH}$. Estimation of the frequency of self-reactive $\mathrm{T}$ cells in health and inflammatory diseases by limiting dilution analysis and single cell cloning. J Autoimmun (1996) 9(5):667-75. doi:10.1006/jaut.1996.0087

83. Anderson AC, Nicholson LB, Legge KL, Turchin V, Zaghouani H, Kuchroo VK. High frequency of autoreactive myelin proteolipid protein-specific $\mathrm{T}$ cells in the periphery of naive mice: mechanisms of selection of the self-reactive repertoire. J Exp Med (2000) 191(5):761-70. doi:10.1084/ jem.191.5.761

84. Enouz S, Carrié L, Merkler D, Bevan MJ, Zehn D. Autoreactive T cells bypass negative selection and respond to self-antigen stimulation during infection. J Exp Med (2012) 209(10):1769-79. doi:10.1084/jem.20120905

85. Walker LS, Abbas AK. The enemy within: keeping self-reactive T cells at bay in the periphery. Nat Rev Immunol (2002) 2(1):11-9. doi:10.1038/ nri701

86. Steinman RM, Turley S, Mellman I, Inaba K. The induction of tolerance by dendritic cells that have captured apoptotic cells. J Exp Med (2000) 191(3):411-6. doi:10.1084/jem.191.3.411

87. Kurts C. Cross-presentation: inducing CD8 T cell immunity and tolerance. J Mol Med (2000) 78(6):326-32. doi:10.1007/s001090000108

88. Adler AJ, Marsh DW, Yochum GS, Guzzo JL, Nigam A, Nelson WG, et al. $\mathrm{CD} 4+\mathrm{T}$ cell tolerance to parenchymal self-antigens requires presentation by bone marrow-derived antigen-presenting cells. JExp Med (1998) 187(10):1555-64. doi:10.1084/jem.187.10.1555

89. Heath WR, Kurts C, Miller JF, Carbone FR. Cross-tolerance: a pathway for inducing tolerance to peripheral tissue antigens. JExp Med (1998) 187(10):1549-53. doi:10.1084/jem.187.10.1549

90. Steinman RM, Hawiger D, Nussenzweig MC. Tolerogenic dendritic cells. Annu Rev Immunol (2003) 21:685-711. doi:10.1146/annurev. immunol.21.120601.141040

91. Blander JM, Medzhitov R. Toll-dependent selection of microbial antigens for presentation by dendritic cells. Nature (2006) 440(7085):808-12. doi:10.1038/ nature 04596

92. Wilson NS, El-Sukkari D, Belz GT, Smith CM, Steptoe RJ, Heath WR, et al. Most lymphoid organ dendritic cell types are phenotypically and functionally immature. Blood (2003) 102(6):2187-94. doi:10.1182/blood2003-02-0513

93. Allan RS, Smith CM, Belz GT, van Lint AL, Wakim LM, Heath WR, et al. Epidermal viral immunity induced by CD8alpha+ dendritic cells but not by Langerhans cells. Science (2003) 301(5641):1925-8. doi:10.1126/ science. 1087576

94. Allan RS, Waithman J, Bedoui S, Jones CM, Villadangos JA, Zhan Y, et al. Migratory dendritic cells transfer antigen to a lymph node-resident dendritic cell population for efficient CTL priming. Immunity (2006) 25(1):153-62. doi:10.1016/j.immuni.2006.04.017

95. Lukacs-Kornek V, Burgdorf S, Diehl L, Specht S, Kornek M, Kurts C. The kidney-renal lymph node-system contributes to cross-tolerance against innocuous circulating antigen. J Immunol (2008) 180(2):706-15. doi:10.4049/ jimmunol.180.2.706

96. Guery L, Hugues S. Tolerogenic and activatory plasmacytoid dendritic cells in autoimmunity. Front Immunol (2013) 4:59. doi:10.3389/fimmu. 2013.00059

97. Lee JW, Epardaud M, Sun J, Becker JE, Cheng AC, Yonekura AR, et al. Peripheral antigen display by lymph node stroma promotes $\mathrm{T}$ cell tolerance to intestinal self. Nat Immunol (2007) 8(2):181-90. doi:10.1038/ni1427

98. Magnusson FC, Liblau RS, von Boehmer H, Pittet MJ, Lee JW, Turley SJ, et al. Direct presentation of antigen by lymph node stromal cells protects against CD8 T-cell-mediated intestinal autoimmunity. Gastroenterology (2008) 134(4):1028-37. doi:10.1053/j.gastro.2008.01.070

99. Collier AY, Lee JW, Turley SJ. Self-encounters of the third kind: lymph node stroma promotes tolerance to peripheral tissue antigens. Mucosal Immunol (2008) 1(4):248-51. doi:10.1038/mi.2008.19

100. Hirosue S, Dubrot J. Modes of antigen presentation by lymph node stromal cells and their immunological implications. Front Immunol (2015) 6:446. doi:10.3389/fimmu.2015.00446
101. Nichols LA, Chen Y, Colella TA, Bennett CL, Clausen BE, Engelhard VH. Deletional self-tolerance to a melanocyte/melanoma antigen derived from tyrosinase is mediated by a radio-resistant cell in peripheral and mesenteric lymph nodes. J Immunol (2007) 179(2):993-1003. doi:10.4049/ jimmunol.179.2.993

102. Fletcher AL, Lukacs-Kornek V, Reynoso ED, Pinner SE, Bellemare-Pelletier A, Curry MS, et al. Lymph node fibroblastic reticular cells directly present peripheral tissue antigen under steady-state and inflammatory conditions. J Exp Med (2010) 207(4):689-97. doi:10.1084/jem.20092642

103. Cohen JN, Guidi CJ, Tewalt EF, Qiao H, Rouhani SJ, Ruddell A, et al. Lymph node-resident lymphatic endothelial cells mediate peripheral tolerance via Aire-independent direct antigen presentation. JExp Med (2010) 207(4): 681-8. doi:10.1084/jem.20092465

104. Cohen JN, Tewalt EF, Rouhani SJ, Buonomo EL, Bruce AN, Xu X, et al. Tolerogenic properties of lymphatic endothelial cells are controlled by the lymph node microenvironment. PLoS One (2014) 9(2):e87740. doi:10.1371/ journal.pone. 0087740

105. Gardner JM, Devoss JJ, Friedman RS, Wong DJ, Tan YX, Zhou X, et al. Deletional tolerance mediated by extrathymic Aire-expressing cells. Science (2008) 321(5890):843-7. doi:10.1126/science.1159407

106. Gardner JM, Metzger TC, McMahon EJ, Au-Yeung BB, Krawisz AK, Lu W, et al. Extrathymic Aire-expressing cells are a distinct bone marrow-derived population that induce functional inactivation of $\mathrm{CD} 4(+) \mathrm{T}$ cells. Immunity (2013) 39(3):560-72. doi:10.1016/j.immuni.2013.08.005

107. Yip L, Su L, Sheng D, Chang P, Atkinson M, Czesak M, et al. Deaf1 isoforms control the expression of genes encoding peripheral tissue antigens in the pancreatic lymph nodes during type 1 diabetes. Nat Immunol (2009) 10(9):1026-33. doi:10.1038/ni.1773

108. Gibson TJ, Ramu C, Gemund C, Aasland R. The APECED polyglandular autoimmune syndrome protein, AIRE-1, contains the SAND domain and is probably a transcription factor. Trends Biochem Sci (1998) 23(7):242-4. doi:10.1016/S0968-0004(98)01231-6

109. Metzger TC, Anderson MS. Control of central and peripheral tolerance by Aire. Immunol Rev (2011) 241(1):89-103. doi:10.1111/j.1600-065X. 2011.01008.x

110. Dubrot J, Duraes FV, Potin L, Capotosti F, Brighouse D, Suter T, et al. Lymph node stromal cells acquire peptide-MHCII complexes from dendritic cells and induce antigen-specific CD4(+) T cell tolerance. J Exp Med (2014) 211(6):1153-66. doi:10.1084/jem.20132000

111. Malhotra D, Fletcher AL, Astarita J, Lukacs-Kornek V, Tayalia P, Gonzalez $\mathrm{SF}$, et al. Transcriptional profiling of stroma from inflamed and resting lymph nodes defines immunological hallmarks. Nat Immunol (2012) 13(5):499-510. doi:10.1038/ni.2262

112. Reith W, LeibundGut-Landmann S, Waldburger JM. Regulation of MHC class II gene expression by the class II transactivator. Nat Rev Immunol (2005) 5(10):793-806. doi:10.1038/nri1708

113. Baptista AP, Roozendaal R, Reijmers RM, Koning JJ, Unger WW, Greuter $\mathrm{M}$, et al. Lymph node stromal cells constrain immunity via MHC class II self-antigen presentation. Elife (2014) 3. doi:10.7554/eLife.04433

114. Ciré S, Da Rocha S, Ferrand M, Collins MK, Galy A. In vivo gene delivery to lymph node stromal cells leads to transgene-specific CD8+ T cell anergy in mice. Mol Ther (2016) 24(11):1965-73. doi:10.1038/mt.2016.168

115. Reynoso ED, Elpek KG, Francisco L, Bronson R, Bellemare-Pelletier A, Sharpe $\mathrm{AH}$, et al. Intestinal tolerance is converted to autoimmune enteritis upon PD-1 ligand blockade. J Immunol (2009) 182(4):2102-12. doi:10.4049/ jimmunol.0802769

116. Tewalt EF, Cohen JN, Rouhani SJ, Guidi CJ, Qiao H, Fahl SP, et al. Lymphatic endothelial cells induce tolerance via PD-L1 and lack of costimulation leading to high-level PD-1 expression on CD8 T cells. Blood (2012) 120(24):4772-82. doi:10.1182/blood-2012-04-427013

117. Tamburini BA, Burchill MA, Kedl RM. Antigen capture and archiving by lymphatic endothelial cells following vaccination or viral infection. Nat Commun (2014) 5:3989. doi:10.1038/ncomms4989

118. Fruhwürth S, Pavelka M, Bittman R, Kovacs WJ, Walter KM, Röhrl C, et al. High-density lipoprotein endocytosis in endothelial cells. World J Biol Chem (2013) 4(4):131-40. doi:10.4331/wjbc.v4.i4.131

119. Nörder M, Gutierrez MG, Zicari S, Cervi E, Caruso A, Guzmán CA. Lymph node-derived lymphatic endothelial cells express functional costimulatory 
molecules and impair dendritic cell-induced allogenic T-cell proliferation. FASEB J (2012) 26(7):2835-46. doi:10.1096/fj.12-205278

120. Diehl L, Schurich A, Grochtmann R, Hegenbarth S, Chen L, Knolle PA. Tolerogenic maturation of liver sinusoidal endothelial cells promotes B7-homolog 1-dependent CD8+ T cell tolerance. Hepatology (2008) 47(1):296-305. doi:10.1002/hep.21965

121. Böttcher JP, Schanz O, Wohlleber D, Abdullah Z, Debey-Pascher S, Staratschek-Jox A, et al. Liver-primed memory $\mathrm{T}$ cells generated under noninflammatory conditions provide anti-infectious immunity. Cell Rep (2013) 3(3):779-95. doi:10.1016/j.celrep.2013.02.008

122. Abe J, Shichino S, Ueha S, Hashimoto S, Tomura M, Inagaki $\mathrm{Y}$, et al. Lymph node stromal cells negatively regulate antigen-specific CD4+ T cell responses. J Immunol (2014) 193(4):1636-44. doi:10.4049/jimmunol. 1302946

123. Roche PA, Furuta K. The ins and outs of MHC class II-mediated antigen processing and presentation. Nat Rev Immunol (2015) 15(4):203-16. doi: $10.1038 / \mathrm{nri} 3818$

124. Duraes FV, Thelemann C, Sarter K, Acha-Orbea H, Hugues S, Reith W. Role of major histocompatibility complex class II expression by nonhematopoietic cells in autoimmune and inflammatory disorders: facts and fiction. Tissue Antigens (2013) 82(1):1-15. doi:10.1111/tan.12136

125. Kambayashi T, Laufer TM. Atypical MHC class II-expressing antigenpresenting cells: can anything replace a dendritic cell? Nat Rev Immunol (2014) 14(11):719-30. doi:10.1038/nri3754

126. Davis DM. Intercellular transfer of cell-surface proteins is common and can affect many stages of an immune response. Nat Rev Immunol (2007) 7(3):238-43. doi:10.1038/nri2020
127. Zhang QJ, Li XL, Wang D, Huang XC, Mathis JM, Duan WM, et al. Trogocytosis of MHC-I/peptide complexes derived from tumors and infected cells enhances dendritic cell cross-priming and promotes adaptive $\mathrm{T}$ cell responses. PLoS One (2008) 3(8):e3097. doi:10.1371/journal.pone.0003097

128. Wakim LM, Bevan MJ. Cross-dressed dendritic cells drive memory CD8+ T-cell activation after viral infection. Nature (2011) 471(7340):629-32. doi:10.1038/nature09863

129. de Heusch M, Blocklet D, Egrise D, Hauquier B, Vermeersch M, Goldman $S$, et al. Bidirectional MHC molecule exchange between migratory and resident dendritic cells. JLeukoc Biol (2007) 82(4):861-8. doi:10.1189/ jlb.0307167

130. Griffin JP, Chu R, Harding CV. Early endosomes and a late endocytic compartment generate different peptide-class II MHC complexes via distinct processing mechanisms. J Immunol (1997) 158(4):1523-32.

131. Clement CC, Santambrogio L. The lymph self-antigen repertoire. Front Immunol (2013) 4:424. doi:10.3389/fimmu.2013.00424

Conflict of Interest Statement: The authors declare that the research was conducted in the absence of any commercial or financial relationships that could be construed as a potential conflict of interest.

Copyright () 2017 Humbert, Hugues and Dubrot. This is an open-access article distributed under the terms of the Creative Commons Attribution License (CC BY). The use, distribution or reproduction in other forums is permitted, provided the original author(s) or licensor are credited and that the original publication in this journal is cited, in accordance with accepted academic practice. No use, distribution or reproduction is permitted which does not comply with these terms. 